\title{
Gastroenterological Society of Australia
}

The fourth annual general meeting of the Gastroenterological Society of Australia was held at Royal Prince Alfred Hospital, Sydney, on 8 June 1963. Following the business meeting a scientific session was held, with the newly elected President, Dr. Stanley Goulston, in the Chair. The following papers were presented.

SMALL INTESTINAL CONSERVATION OF SODIUM DURING SODIUM DEPLETION IN MAN

A. P. SKYRING, N. D. GALlAGHER, and D. D. HARRISON Profuse diarrhoea, especially from an ileostomy, is capable of producing marked salt and water depletion. The role of the kidney in the correction of these abnormalities is well known but the ability of the small intestine to modify its losses is not so well recognized. A 30-day study was performed on a patient with an ileostomy and steatorrhoea during a period of severe salt depletion and during gradual recovery.

In the first five-day period neither sodium nor potassium were present in the urine and the ileostomy electrolyte concentrations were of the order of $80 \mathrm{mEq}$./litre of sodium and $40 \mathrm{mEq} . / \mathrm{l}$. of potassium. In the second five-day period potassium appeared in the urine but there was no change in ileostomy electrolytes. In the third and fourth five-day periods, there were increasing quantities of potassium in the urine (up to $70 \mathrm{mEq}$./l.) but no sodium was present. The ileostomy electrolyte concentrations during these periods were sodium 80 to $100 \mathrm{mEq}$./l. and potassium 26 to $40 \mathrm{mEq}$./l. In period five sodium appeared in the urine for the first time and there was an abrupt change in ileostomy electrolytes so that by the middle of period six the concentrations had fallen to sodium $120 \mathrm{mEq}$./l. and potassium $8 \mathrm{mEq} . / 1$.

These results suggest that the small bowel can make a significant contribution to sodium conservation in the salt-depleted patient and that the changing ileal electrolytes in such a patient can lead to superimposed potassium depletion.

\section{THE OLYMPUS GASTROCAMERA}

A. P. SKYRING The Olympus gastrocamera, invented and manufactured in Japan in 1959, was described and the technique of its operation outlined. One hundred and thirty-two patients were studied, and the pictures obtained in a number of these were shown. The Olympus gastrocamera appears a useful diagnostic aid particularly in centres where gastroscopy is not available and mainly for lesions of the gastric antrum. The failure rate in the middle and upper thirds of the body of the stomach makes it of limited use in the differential diagnosis of ulcers in this region.

\section{PROTEIN LOSS INTO THE GUT IN CONGESTIVE CARDIAC FAILURE}

B. HANEMAN Increased loss of albumin into the gut has already been documented in constrictive pericarditis, pulmonary stenosis, and atrial septal defect, but to date not in the more commonplace types of heart failure. In this study albumin loss was increased in six cases of congestive cardiac failure, three due to ischaemic heart disease and three due to cor pulmonale.

Albumin turnover was studied using the method of Coghill and Jeejeebhoy. Blocking doses of iodine were given twice daily and five doses daily of Amberlite resin. The iodinated albumin was prepared by a modification of McFarlane's jet iodination technique using undenatured human serum albumin.

All the patients studied had a lowered serum albumin level. In each case a loss of albumin into the gut greater than in normal subjects could be demonstrated. The lower the serum albumin level the greater was the apparent rate of loss. The possible errors introduced in this method either due to salivary iodine excretion or due to altered renal function were discussed.

Reduced synthesis of albumin was also demonstrated and this reduction rather than the albumin loss determines the level to which the serum albumin will ultimately fall.

\section{JEJUNITIS WITH ULCERATION AND PERFORATION}

K. J. GOULSTON Four cases were described all of which had ulcerative jejunitis associated with evidence of malabsorption. None of the usual known cases of jejunitis were found and the aetiology of this group of cases is unknown. The mucosa adjacent to the ulcerations resembled the sprue pattern histologically and in fact two of these cases were diagnosed and treated as idiopathic steatorrhoea and responded clinically to a gluten-free diet. Three of the four cases perished and the complications included haemorrhage, perforation, and obstruction. One case responded clinically to steroid therapy but still had evidence of gross malabsorption.

\section{HEPATIC CHANGES FOLLOWING REOVIRUS III} INFECTION IN INFANT MICE

R. A. JOSKE, P. M. LEAK, N. F. STANLEY, and N. M. I. WALTERS Infant mice infected with reovirus type III by the oral, intraperitoneal or intracerebral routes regularly develop a progressive disease characterized in the acute phase by retardation of growth, jaundice, steatorrhoea, oily hair effect, ataxia, and other signs. Many mice die in this acute stage, but a proportion survive into a chronic illness. At necropsy lesions are present in the liver, pancreas, heart, and central nervous system in all animals with variable changes in other organs. 
The hepatic lesions appear on the fourth day as small aggregates of mononuclear cells. These increase in size and eosinophilic necrosis of large areas of the liver develops. Councilman bodies are frequent. In the third week cystic degeneration of the eosinophilic areas occurs with regeneration from hepatocytes and bile ductular cells. There is a sudden exacerbation of the lesions in the fifth week, with later development of either a picture resembling that seen after biliary obstruction, or further collections of pathologically acute lesions with bizarre nuclear changes in hepatic parenchymal cells.

The pathogenesis of the changes is uncertain, but a chronic virus infection or some immune mechanism has been suggested.

\section{CHANGES IN EXTERIORIZED DUODENAL MUCOSA}

F. O. STEPHENS and E. S. FINCKH Extensive studies were made of the reaction of trauma and environmental changes of gastric mucous membrane, but very little is known of the changes which occur in duodenal mucosa under similar conditions. In this study changes were observed in duodenal mucosa after it had been exteriorized onto the abdominal wall, and the effects of covering the exteriorized mucosa with skin flaps after several months' exposure were also recorded.

Macroscopically the explant remained pink and moist, apparently for the duration of the experiment, and always retained its ability to make peristaltic movements in response to stimulation. It did shrink a little in surface area and the surface became gradually smooth and uniform in appearance. Histological changes in the explanted mucosa occurred quite rapidly. The villi became shortened and completely disappeared after two weeks. The mucous membrane underwent degenerative changes similar to those in explanted gastric mucosa. After two months the mucous membrane was composed of cystic glands lined by regular columnar cells, and was indistinguishable from explanted gastric mucous membrane at the same stage.

Covering the explanted mucosa with skin flaps resulted in rapid recovery of the normal macroscopic and microscopic features of duodenal mucous membrane.

\section{REHABILITATION OF PATIENTS WITH AN \\ ILEOSTOMY PERFORMED IN THE TREATMENT OF ULCERATIVE COLITIS}

E. WILSON Contact with patients who have an ileostomy soon engenders an admiration for the ease, rapidity, and degree of completeness of their rehabilitation; but, the knowledge that such satisfactory rehabilitation is possible is not widespread, even though it could greatly influence the decision to submit a patient with ulcerative colitis to operation. This being so, the present status of a series of 98 patients with an ileostomy performed in the treatment of ulcerative colitis was recently reviewed, and the results presented.

With the odd exception these patients were soon reinstated in the community as apparently normal individuals; but, about three hours a week have been required to look after the ileostomy, the average cost per year for ileostomy appliances has been A£22 10s, more than a third of the patients have required another operation for the treatment of a complication since having the ileostomy, and in two-thirds of the patients some dietary restriction has been necessary. However, these patients consider that an ileostomy and the above problems are only a very small price to pay for good health and a happy existence.

\section{SERUM PEPSINOGEN AND GASTRIC ACID SECRETION}

R. S. PACKARD, A. P. SKYRING, and D. D. HARRISON The augmented histamine test has been shown to provide a maximal stimulus to acid secretion by the stomach. The results of this test are adequately reproducible. It has also been shown that a correlation exists between the acid output of the stomach measured in this way and the parietal cell mass. Serial estimations of serum pepsinogen have likewise been shown to be satisfactorily reproducible. Despite a good deal of conjecture the precise significance of the serum pepsinogen remains unknown.

Determination of maximal acid secretion of the augmented histamine tests and estimation of serum pepsinogen have both been performed in approximately 100 patients with duodenal ulcer, gastric ulcer, and a variety of other disorders. The results show a correlation between acid output and serum pepsinogen. The possible theoretical and practical applications of these findings were discussed.

\section{ILEORECTAL ANASTOMOSIS FOR ULCERATIVE COLITIS}

E. S. R. HUGHeS A series of 31 patients subjected to ileorectal anastomosis for ulcerative colitis was presented. Four patients died, one from carcinoma six months later, and the other three following operation. Of the remaining 27 cases, 12 were excellent, 10 fair, and five were failures.

The 12 cases classified as 'excellent' settled down quickly after operation. They were continent, had little tendency to exacerbations of diarrhoea, had few food troubles, and rarely took medicine. These patients had from one to four bowel actions during the day and none at night.

Each of the 10 cases classified as 'fair' had at least one bowel action during the night and about five to six during the day. They were happy with the result.

All five 'failures' had the ileostomy restored. It was difficult to find why these failed. It seems desirable to save as much ileum as possible.

BOWEL FUNCTION FOLLOWING SUBTOTAL COLECTOMY FOR CARCINOMA OF THE COLON

A. M. CUTHBERTSON A series of 27 cases of subtotal colectomy for carcinoma was reviewed in order to determine the functional results. The rectum was normal and in most cases only a few centimetres of terminal ileum were removed. An ileodescending anastomosis was done in six cases, ileosigmoid in 17, and four had an ileorectal anastomosis. All but three had an excellent functional result, having less than five bowel actions 
during the day and none at night. Two of the three patients having more than five bowel actions per day had previously had a gastro-jejunostomy carried out for duodenal ulcer.

It does appear that after subtotal colectomy with anastomosis most patients have normal motions which are retained without difficulty provided that the rectum is normal.

The Gastroenterological Society conducted their clinical meeting at the meeting of the Royal Australasian College of Physicians at the University of New South Wales on 7 June. The following cases were presented:'Liver disease and intestinal malabsorption' by R. S. Packard; 'Primary acquired agammaglobulinaemia and intestinal malabsorption' by Sir William Morrow; 'Hodgkin's disease and intestinal malabsorption' by P. Harvey; 'Coeliac disease in a family' by D. J. Fone; and 'Small intestinal sucrase and iso-maltase deficiency in a family' by Charlotte M. Anderson.

\section{The August 1964 Issue}

\section{THE AUGUST 1964 ISSUE CONTAINS THE FOLLOWING PAPERS}

Gastric epithelium in the duodenum A. H. JAMES

Studies on the mechanism of destruction of the toxic action of wheat gluten in coeliac disease by crude papain M. MESSER, CHARLOTTE M. ANDERSON, and LOIS HUBBARD

Sideroblastic anaemia in adult coeliac disease A. M. DAWSON, C. D. HOLDSWORTH, and C. S. PITCHER

Steatorrhoea in rats with an intestinal cul-de-sac P. P. HOET and H. EYSSEN

Reticulum cell sarcoma of the small bowel and steatorrhoea DOUGLAS EAKINS, TERENCE FULTON, and DAVID R. HADDEN

Further observations on the gastric secretory depressant in human gastric juice PETER B. ROWE, BARBARA H. FENTON, and DEBORAH BEESTON

Studies on gastrin K. S. LAI

Part I A method of biological assay on gastrin

Part II Quantitative study of the distribution of gastrinlike activity along the gut

Part III Gastrin-like activity in stomachs of patients with peptic ulceration and gastric carcinoma
Inhibitory effect of secretin and cholecystokinin on Heidenhain pouch responses to gastrin extract and histamine IAIN E. GILLESPIE and MORTON I. GROSSMAN

On the use of tritium-labelled albumin for studies of intestinal absorption K. N. JEEJEEBHOY, J. H. STEWART, E. A. EVANS, and C. C. BOOTH

Exfoliative cytology and autoradiography using ${ }^{32} \mathrm{P}$ A. M. BAPTISTA, A. L. BASTOS, and M. E. SILVESTRE

Peptic ulcer in Assam s. L. Malhotra, C. T. MaJumdar, and P. C. BARDOLOI

Watery diarrhoea and an islet cell tumour W. HINDLE, D. J. MCBRIEN, and B. CREAMER

Superior mesenteric embolectomy G. L. BOHN and K. J. CARROLL

The intraluminal pressure patterns in diverticulosis of the colon NEIL STAMFORD PAINTER and S. C. TRUELOVE

\section{Part III The effect of prostigmine}

Part IV The effect of pethidine and probanthine

Iron loading and the liver: the effect on regeneration after partial hepatectomy M. C. BRAIN

Copies are still available and may be obtained from the PUBLISHING MANAGER, BRITISH MEDICAL ASSOCIATION, TAVISTOCK SQUARE, W.C.I., price 18s. 6D. 